\title{
La aplicación del Principio de Subsidiariedad en la jurisprudencia de la Corte Interamericana de Derechos Humanos: avances y retos The application of the Principle of Subsidiarity in the jurisprudence of the Inter-American Court of Human Rights: progresses and challenges
}

Georgina Vargas Vera ${ }^{1}$

Comisión Nacional de los Derechos Humanos de México

\section{Resumen}

Históricamente, el principio de subsidiariedad ha servido como un mecanismo de ponderación de valores y derechos protegidos por el derecho internacional de los derechos humanos (DIDH). La Corte Interamericana de Derechos Humanos (Corte IDH) ha emitido sentencias aplicando el principio de subsidiariedad, muchas veces sin una precisión adecuada. Cabe recalcar que, en la reciente jurisprudencia, se han podido observar ciertos avances en la materia, aunque no los suficientes. Este artículo analizará en un primer momento el principio de subsidiariedad y su entendimiento por parte de la Corte IDH; posteriormente señalará la relación del principio de subsidiariedad con el artículo 2 de la Convención Americana sobre Derechos Humanos $(\mathrm{CADH})$; y después estudiará la aplicación de dicho principio en algunas sentencias recientes de la Corte IDH. Se concluirá resaltando la buena práctica que resulta de la correcta aplicación del principio de subsidiariedad por parte de la Corte IDH, y los retos futuros que esta puede enfrentar. Siempre en aras de ampliar su desarrollo en la jurisprudencia interamericana.

\section{Palabras clave}

Aplicación del principio de subsidiariedad / Corte Interamericana de Derechos Humanos / Convención Interamericana sobre Derechos Humanos / Derecho internacional de los derechos humanos / Correcta aplicación del principio / Retos futuros.

\section{Summary}

Historically, the principle of subsidiarity has served as a mechanism for weighing values and rights protected by international human rights law (IHRL). The Inter-American Court of Human Rights has issued rulings applying the principle of subsidiarity, often without an adequate precision. It should be noted that in the recent jurisprudence, certain advances have been observed, but not enough, in the matter. This article will analyze, at first, the principle of subsidiarity and its understanding by the Inter-American Court; subsequently, it will indicate the relationship of the principle of subsidiarity with Article 2 of the American Convention on Human Rights (ACHR); Afterwards, it will study the application of the mentioned principle in some recent statements of the Inter-American Court. It concludes by highlighting the good practice that results from the correct application of the principle of subsidiarity by the Inter-American Court, and the future challenges it may face. Always in order to expand its development in the inter-American jurisprudence.

\section{Recibido: 15/08/2018 - Aceptado: 27/04/2018}

1 Subdirectora de área en la Comisión Nacional de los Derechos Humanos de México. Anteriormente fue abogada de la Corte Interamericana de Derechos Humanos y trabajó en diversas organizaciones de la sociedad civil en México. Es abogada por la Universidad Iberoamericana (México) y maestra en derecho internacional de los derechos humanos por la Universidad de Notre Dame (Estados Unidos de América). 


\section{Keywords}

Application of the principle of subsidiarity / Inter-American Court of Human Rights / InterAmerican Convention on Human Rights / International Law of Human Rights / Correct application of the principle / Future challenges.

\section{El Principio de Subsidiariedad}

El principio de subsidiariedad puede ser entendido como el principio con base en el cual cada grupo social y político debe ayudar a grupos más locales o pequeños a alcanzar sus respectivos fines, sin que se atribuya esas tareas a sí mismo (Carozza, 2003).

En relación con el DIDH y su interacción con el principio de subsidiariedad, Paolo Carozza explica que existe una tensión inherente entre la afirmación de una visión sustantiva universal de la dignidad humana, y el respeto a la diversidad y la libertad de las culturas. De acuerdo con Carozza, aunque la comprensión y la defensa de los derechos humanos en el derecho internacional requieren que nos enfrentemos a esa tensión, las nociones clásicas de soberanía estatal (monismo o dualismo) no pueden hacerse cargo del problema que implica resolverlo. El principio de subsidiariedad, en cambio, nos da una herramienta conceptual para mediar la polaridad del pluralismo y el bien común en un mundo globalizado, el cual ayuda a darle sentido al derecho internacional de los derechos humanos (Carozza, 2003).

La formulación general del principio de subsidiariedad es relativamente sencilla: la subsidiariedad requiere que a las comunidades locales se les permita proteger y respetar la dignidad humana siempre que puedan lograr estos fines por sí mismos. En la medida en que los organismos locales no puedan lograr sus fines respecto a derechos humanos, las comunidades más grandes de la sociedad internacional tienen la responsabilidad de intervenir. En la medida de lo posible, el subsidio de la comunidad más grande debe estar orientado a ayudar a la menor, a alcanzar su objetivo sin suplantar o usurpar la libertad de esta última, para perseguir sus propios fines legítimos (Carozza, 2003).

La noción de subsidiariedad (referida indistintamente como complementariedad) puede verse plasmada en el preámbulo de la $\mathrm{CADH}$, donde se reconoce que,

los derechos esenciales del hombre no nacen del hecho de ser nacional de determinado Estado, sino que tienen como fundamento los atributos de la persona humana, razón por la cual justifican una protección internacional, de naturaleza convencional coadyuvante o complementaria de la que ofrece el derecho interno de los Estados americanos (Preámbulo CADH, 1969; énfasis añadido).

Asimismo, la naturaleza coadyuvante y complementaria del Sistema Interamericano de Derechos Humanos (SIDH) ha sido reconocida por la Corte IDH. Esta indica que la responsabilidad estatal bajo la $\mathrm{CADH}$ sólo puede ser exigida a nivel internacional después de que los Estados hayan tenido la oportunidad de reconocer, en su caso, una violación de un derecho y reparar el daño ocasionado por sus propios medios. Lo anterior se asienta en el principio de complementariedad, que orienta transversalmente el SIDH, el cual es, tal como lo expresa el Preámbulo de la $\mathrm{CADH}$, coadyuvante o complementario de la protección que ofrece el derecho interno de los Estados americanos. El Estado es el principal garante de los derechos humanos de las personas, de manera que, si se produce un acto violatorio de dichos derechos, es el propio Estado quien tiene el deber de resolver el asunto a nivel interno y, en su caso, reparar. Esto, antes de tener que responder ante instancias internacionales como 
el SIDH, lo cual deriva del carácter subsidiario que reviste el proceso internacional frente a los sistemas nacionales de garantías de los derechos humanos (Corte IDH, Caso Acevedo Jaramillo y otros Vs. Perú, 2006, párr. 66; Caso Comunidad Campesina de Santa Bárbara Vs. Perú, 2015, párr.159; Caso Duque Vs. Colombia, 2016, párr. 128).

La Corte IDH ha señalado que el referido carácter complementario de la jurisdicción internacional significa que el sistema de protección instaurado por la $\mathrm{CADH}$, no sustituye a las jurisdicciones nacionales, sino que las complementa (Corte IDH. Caso Tarazona Arrieta y otros Vs. Perú, 2014, párr. 137; Caso Comunidad Campesina de Santa Bárbara Vs. Perú, 2015, párr. 159; Caso Duque Vs. Colombia, 2016, párr. 128).

Vale la pena destacar que la Corte IDH ha utilizado el concepto de complementariedad, que aparece en el preámbulo de la $\mathrm{CADH}$, como un sinónimo de la subsidiariedad; ambos conceptos han sido empleados por el Tribunal en sus sentencias de manera indistinta, señalando en un principio la subsidiariedad (Caso Valle Jaramillo Vs. Colombia), para posteriormente indicar, entre paréntesis, la naturaleza subsidiaria del SIDH (Caso Masacre de Santo Domingo Vs. Colombia), y en casos más recientes señalar directamente la noción de complementariedad (Caso Duque Vs. Colombia).

\section{El Principio de Subsidiariedad en relación con el Artículo 2 de la Convención America- na sobre Derechos Humanos}

Puede considerarse que el artículo 1.1 de la $\mathrm{CADH}$ se refiere a las obligaciones de respetar y garantizar los derechos y las libertades (obligaciones de aplicación "directa” y cuyo incumplimiento genera la consecuente responsabilidad internacional del Estado); mientras que el artículo 2 agrega el compromiso, de ser el caso, en el que los derechos y las libertades no estuvieren ya garantizados por el derecho interno, de adoptar las medidas legislativas o de otro carácter que fueren necesarias (Ferrer, E., Pelayo, C., 2014, pp. 69-98).

El artículo 2 de la $\mathrm{CADH}$ establece lo siguiente:

Deber de Adoptar Disposiciones de Derecho Interno. Si el ejercicio de los derechos y libertades mencionados en el artículo 1 no estuviere ya garantizado por disposiciones legislativas o de otro carácter, los Estados Partes se comprometen a adoptar, con arreglo a sus procedimientos constitucionales y a las disposiciones de esta Convención, las medidas legislativas o de otro carácter que fueren necesarias para hacer efectivos tales derechos y libertades (CADH, 1969).

El contenido del artículo 2 podría ser interpretado sobre las bases del dualismo o del monismo. Una aproximación dualista, llevaría a concluir que su naturaleza es la de una norma programática, pues los Estados gozan de una libertad absoluta para determinar las medidas legislativas, o de otro carácter, para hacer efectivos los derechos y libertades reconocidos por la CADH. Una interpretación monista, llevaría a concluir que la $\mathrm{CADH}$ es suprema al derecho nacional en virtud de dicho artículo, por lo que la incompatibilidad entre una norma nacional y una convencional, derivaría en la invalidez inmediata de la norma nacional. Sin embargo, es posible determinar que el artículo 2 tiene más sentido cuando se interpreta a la luz del principio de subsidiariedad. Desde esta óptica, la obligación de los Estados de adoptar "medidas legislativas o de otro carácter" (CADH, 1969) implica reconocer la primacía de las instituciones estatales, para definir el tipo de medidas necesarias para garantizar la efectividad de los derechos humanos en el ámbito nacional, pero también permite concluir que el Estado compromete su responsa- 
bilidad internacional, cuando su derecho o prácticas internas son manifiestamente contrarias al contenido sustantivo de un derecho humano (González, P., 2017, pp. 717-748).

Analizando el contenido del artículo 2 y las posibles interpretaciones del mismo, la Corte IDH ha indicado que el deber general del artículo 2 de la CADH, implica la adopción de medidas en dos vertientes. La Corte IDH ha interpretado que tal adecuación implica la adopción de medidas en dos vertientes, a saber: i) la supresión de las normas y prácticas de cualquier naturaleza que entrañen violación a las garantías previstas en la $\mathrm{CADH}$ o que desconozcan los derechos allí reconocidos u obstaculicen su ejercicio, y ii) la expedición de normas y el desarrollo de prácticas conducentes a la efectiva observancia de dichas garantías (Corte IDH. Caso La Cantuta Vs. Perú, 2006, párr. 172, y Caso "La Última Tentación de Cristo" (Olmedo Bustos y otros) Vs. Chile, 2001, párr. 85).

De acuerdo con la Corte IDH, la CADH establece en su artículo 2 la obligación general de cada Estado Parte de adecuar su derecho interno a las disposiciones de la misma, para garantizar los derechos en ella consagrados (Corte IDH. Caso La Cantuta Vs. Perú, 2006, párr. 171, y Caso "Cinco Pensionistas", 2003, párr. 164), lo cual implica que las medidas de derecho interno han de ser efectivas (principio de effet utile) (Corte IDH. Caso La Cantuta Vs. Perú, 2006, párr. 171, y Caso "Instituto de Reeducación del Menor" Vs. Paraguay, 2004, párr. 205). Esto implica que la adecuación de la normativa nacional con la $\mathrm{CADH}$ permite que dicha normativa sea efectiva o útil, es decir que la protección y garantía de los derechos humanos efectivamente sean asegurados mediante estas normas.

Además, la Corte IDH ha señalado que el artículo 2 de la CADH no define cuáles son las medidas pertinentes para la adecuación del derecho interno a la misma, evidentemente por depender ello, del carácter de la norma que la requiera y las circunstancias de la situación concreta (Corte IDH. Caso La Cantuta Vs. Perú, 2006, párr. 172, y Caso "La Última Tentación de Cristo" (Olmedo Bustos y otros) Vs. Chile, 2001, párr. 85).

Cabe resaltar que el Tribunal Interamericano ha entendido que la obligación de la primera vertiente se incumple mientras la norma o práctica violatoria de la $\mathrm{CADH}$ se mantenga en el ordenamiento jurídico (Corte IDH. Caso "La Última Tentación de Cristo" (Olmedo Bustos y otros) Vs. Chile, 2001, párrs. 87-90) y, por ende, se satisface con la modificación (Corte IDH. Caso Hilaire, Constantine y Benjamin y otros Vs. Trinidad y Tobago, 2002, párr. 113), la derogación, o de algún modo anulación (Corte IDH. Caso Caesar Vs. Trinidad y Tobago, 2005, párrs. 91, 93 y 94), o la reforma (Corte IDH. Caso Almonacid Arrellano y otros Vs. Chile, 2006, Párr. 118, y Caso Raxcacó Reyes Vs. Guatemala, 2005, Párr. 87) de las normas o prácticas que tengan esos alcances, según corresponda (Corte IDH. Caso La Cantuta Vs. Perú, 2006, párr. 172).

En relación con la segunda obligación, la Corte IDH analiza que los Estados hayan desarrollado prácticas y expedido recursos que permitan el respeto y el goce de los derechos contenidos en la CADH. En ese sentido, la Corte IDH ha conocido casos relacionados con la creación de recursos adecuados para la protección de derechos (Corte IDH. Caso Maldonado Vargas y otros Vs. Chile, 2015), y con la instauración de mecanismos y prácticas por parte de agentes estatales para garantizar los derechos de las personas (Corte IDH. Caso Velásquez Paiz y otros Vs. Guatemala, 2015). La creación de recursos adecuados ha permitido garantizar, entre otros, derechos a las garantías judiciales, derecho a la propiedad, derecho a la no discriminación, derecho a la protección de la integridad personal, entre otros.

El derecho internacional establece límites estrictos a la conducta de los Estados en aquellas cuestiones que constituyen una violación a la dignidad humana en cualquier circunstancia. No obstante, existe un importante margen de libertad para los Estados en la interpretación de aquellos derechos que tienen una dimensión política o social. Por ejemplo, 
la jurisprudencia del SIDH, establece una estricta regulación a los Estados en lo que respecta al derecho a la integridad personal, pues prohíbe el sometimiento de una persona a tortura o a tratos crueles, inhumanos y degradantes. No permite ninguna limitación ni suspensión de este derecho, y ha desarrollado a detalle su contenido. Mas no se puede decir lo mismo, por ejemplo, del derecho a la libertad de pensamiento y de expresión, cuyos términos son mucho más abiertos a la interpretación: se admiten limitaciones y suspensiones en cumplimiento de las condiciones establecidas por la propia CADH (González, P., 2017, pp. 717-748).

El desarrollo del contenido del artículo 2 de la $\mathrm{CADH}$, a la luz del principio de subsidiariedad, permitiría entender que, en el caso de que los Estados no garanticen a nivel interno los derechos contenidos en el artículo 1 de la $\mathrm{CADH}$, tendrán que tomar medidas para hacerlo. Es decir, contempla la obligación de que los Estados garanticen y hagan efectivos los derechos y las libertades de sus habitantes. De no ser así, el SIDH, de forma complementaria, podrá determinar la responsabilidad del Estado y la necesidad de tomar medidas para reparar los derechos violados.

El principio de subsidiariedad justifica que la CADH establezca límites objetivos en relación con las normas y prácticas que los Estados deben adoptar para cumplir con sus obligaciones internacionales en materia de derechos humanos. Así, permite concluir que la libertad reconocida por el artículo 2 no es un "cheque en blanco" para que los Estados adopten cualquier medida de derecho interno para garantizar la efectividad de la $\mathrm{CADH}$, o para que no adopten ninguna medida para producir ese resultado. Sino que evita la posición monista que supone la invalidez inmediata de las normas o prácticas nacionales que sean contrarias a los estándares internacionales en la materia, al establecer un límite a las instituciones internacionales para pronunciarse sobre la existencia de normas no convencionales. La subsidiariedad reconoce que el Estado debe conducir sus acciones conforme a los estándares definidos en el derecho internacional de los derechos humanos, al mismo tiempo que este goza de libertad para especificar cuál es la mejor manera de incorporar esos estándares de conformidad con su derecho procesal interno, sus principios y valores constitucionales. Asimismo, de definir los aspectos periféricos del contenido sustantivo de los derechos humanos de fuente internacional (González, P., 2017, pp. 717-748).

Se analizarán, específicamente, algunas sentencias recientes de la Corte IDH en las que se haya empleado el principio de subsidiariedad, con relación a la supresión de normas que entrañen violación a las garantías previstas en la $\mathrm{CADH}$, y a la expedición de normas o prácticas conducentes a la efectiva observancia de dichas garantías.

\section{Aplicación del Principio de Subsidiariedad en las Sentencias de la Corte Interamericana De Derechos Humanos}

Como ya se mencionó, la Corte IDH ha reconocido la naturaleza complementaria del SIDH. Derivado de eso, la Corte IDH, ha aplicado el principio de subsidiariedad en algunas de sus sentencias, reconociendo las modificaciones legislativas de los Estados, cuando estos han dado cumplimiento a la obligación de adoptar disposiciones a nivel interno que deriva del artículo 2 de la $\mathrm{CADH}$.

A continuación, se hará un análisis de tres sentencias recientes del Tribunal Interamericano para estudiar la forma en la que se ha aplicado el principio de subsidiariedad en la determinación de responsabilidad estatal por la violación del artículo 2.

En el caso Tarazona Arrieta y otros Vs. Perú, la Corte IDH debía analizar la responsabilidad internacional del Estado con respecto a la muerte de Zulema Tarazona Arrieta y Norma Pérez Chávez, y las lesiones causadas a Luis Bejarano Laura, como consecuencia de un disparo por parte 
de un miembro del Ejército, contra un vehículo de transporte público en el que se encontraban las referidas víctimas. La Corte IDH resaltó que la víctima sobreviviente y los familiares de las personas fallecidas habían sido reparadas a nivel interno (Corte IDH. Caso Tarazona Arrieta y otros Vs. Perú, 2014, párr. 135).

Tomando eso en consideración, la Corte IDH recordó que el SIDH parte de una instancia nacional, la cual consiste en la obligación de cada Estado de garantizar los derechos y libertades a nivel interno previstos en la $\mathrm{CADH}$, así como de sancionar las infracciones que se cometieren. Si un caso concreto no es solucionado en la etapa interna o nacional, la CADH prevé una instancia internacional en la que los órganos principales son la Comisión Interamericana de Derechos Humanos (CIDH) y la Corte IDH. Además, la Corte IDH señaló que cuando una cuestión ya ha sido resuelta definitivamente en el orden interno, según las cláusulas de la $\mathrm{CADH}$, no es necesario traerla a la Corte IDH para su aprobación o confirmación (Corte IDH. Caso Tarazona Arrieta y otros Vs. Perú, 2014, párr. 136).

La Corte IDH reiteró que la responsabilidad estatal bajo la $\mathrm{CADH}$ sólo puede ser exigida a nivel internacional después de que el Estado haya tenido la oportunidad de establecer, en su caso, una violación de un derecho y, de haber podido reparar el daño ocasionado, por sus propios medios. Resaltando que este entendimiento se asienta en el principio de complementariedad (o subsidiariedad), que informa transversalmente el SIDH, también expresado en el Preámbulo de la misma $\mathrm{CADH}$; coadyuvante o complementario de la protección que ofrece el derecho interno de cada uno de los Estados americanos. De tal manera, el Estado es el principal garante de los derechos humanos de las personas. De manera que, si se produce un acto violatorio de dichos derechos, es el propio Estado quien tiene el deber de resolver el asunto a nivel interno y, en su caso, repararlo. Esto, antes de responder ante instancias internacionales como el SIDH, lo cual deriva del carácter subsidiario que reviste el proceso internacional frente a los sistemas nacionales de garantía de derechos humanos (Corte IDH. Caso Tarazona Arrieta y otros Vs. Perú, 2014, párr. 137).

En el caso Tarazona, la Corte IDH resaltó que la petición inicial del caso había sido presentada ante la CIDH el 22 de enero de 1996, aproximadamente cuatro meses después del archivo del caso por parte del Juzgado Penal, cuando el Estado aún no había procesado penalmente al responsable de los hechos, ni tampoco reparado a las presuntas víctimas. El 3 de junio de 2013, la CIDH sometió el caso a conocimiento de la Corte IDH; período de más de 17 ańos a partir de la presentación de la petición inicial (Corte IDH. Caso Tarazona Arrieta y otros Vs. Perú, párr. 138).

La Corte IDH enfatizó que, en el referido período de tiempo, durante el cual el caso estuvo en conocimiento de la $\mathrm{CIDH}$, el proceso penal a nivel interno fue desarchivado, los hechos investigados, el responsable juzgado y condenado, y las presuntas víctimas reparadas por las autoridades peruanas. $\mathrm{La} \mathrm{CIDH}$, en su escrito para someter el caso ante la Corte IDH, reconoció que lo anterior implicaba que la alegada violación de los derechos a la vida e integridad personal había sido reparada parcialmente. Sin embargo, en sus observaciones finales, presentadas en la audiencia pública del caso, la CIDH señaló que se había visto "en la necesidad de presentar a la Corte IDH un caso cuya solución no resultaba completa ni exigía mayores esfuerzos por parte del Estado", entre otros, por "la necesidad de obtención de justicia ante el incumplimiento de las recomendaciones por parte del Estado de Perú", porque "el Estado indicó que no cumpliría con la recomendación", ni con "la solicitud expresa de las víctimas y sus familiares" (Corte IDH. Caso Tarazona Arrieta y otros Vs. Perú, 2014, párr. 139).

Analizando lo anterior, la Corte IDH consideró que los órganos de administración de justicia penal peruanos habían investigado la prueba de manera efectiva, procesado y condenado al responsable de lo acontecido, y reparado pecuniariamente. Por lo tanto, en las circunstancias 
particulares del caso y tomando en cuenta lo establecido en la CADH, la Corte IDH consideró que, en aplicación del principio de complementariedad, no resultaba necesario analizar las alegadas violaciones de los derechos a la vida y a la integridad personal (Corte IDH. Caso Tarazona Arrieta y otros Vs. Perú, 2014, párr. 140).

El caso Tarazona resulta trascendental debido a la importancia que la Corte IDH dio a la administración de justicia realizada por los tribunales peruanos a nivel interno. El entendimiento de la Corte IDH, de su rol coadyuvante y complementario, quedó de manifiesto al respetar las actuaciones estatales y reconocer que ya habían sido tomadas las acciones necesarias en la esfera nacional, por lo que no era necesario ni adecuado, una doble revisión por parte de un organismo internacional.

La Corte IDH realizó una valoración que permite respetar la naturaleza coadyuvante del SIDH, y considerar que los Estados son los principales garantes de los derechos humanos de las personas. Si el propio Estado ha resuelto el asunto a nivel interno y, en su caso, lo ha reparado, no hay una necesidad de que el SIDH ejecute un análisis posterior para analizar y /o reparar la violación.

Posterior a la sentencia del caso Tarazona, en el caso Cruz Sánchez y otros Vs. Perú, la CIDH requirió a la Corte IDH que analizara la interpretación realizada por la Corte Suprema de Justicia de la República del Perú, al dirimir la contienda de competencia entre la jurisdicción penal ordinaria y la militar. Ello, en virtud de la jurisprudencia de la Corte IDH, en relación con el alcance de la competencia del fuero militar (Corte IDH. Caso Cruz Sánchez y otros Vs. Perú, 2015, párr. 412). Al respecto, la Corte IDH consideró que no estaba bajo análisis la legislación peruana, sino la práctica de las autoridades internas a través de la decisión que había dirimido la contienda de competencia. La Corte Suprema de Justicia de la República, había extendido la competencia del fuero castrense a delitos que no tenían estricta conexión con la disciplina militar o con bienes jurídicos propios del ámbito castrense, ignorando de este modo, la interpretación que de tales garantías había realizado la Corte IDH en relación con el alcance de la jurisdicción penal militar (Corte IDH. Caso Cruz Sánchez y otros Vs. Perú, 2015, párr. 413).

La Corte IDH determinó que esa decisión había sido dictada para el caso concreto y que posteriormente, tanto el Tribunal Constitucional como la Corte Suprema de Justicia de la República habían modificado dicha práctica. Se establecieron criterios de carácter general y vinculante, en el sentido de que el fuero militar debía restringirse a delitos de función determinables por el bien jurídico protegido y no a delitos comunes que impliquen violaciones a los derechos humanos (Corte IDH. Caso Cruz Sánchez y otros Vs. Perú, 2015, párr. 414). En consecuencia, la Corte no encontró violación del artículo 2 de la $\mathrm{CADH}$, en relación a los artículos 8 y 25 de la misma (Corte IDH. Caso Cruz Sánchez y otros Vs. Perú, 2015, párr. 415).

A través del conocimiento del caso Cruz Sánchez por la Corte IDH, se puso en evidencia, que la práctica de las autoridades judiciales y los criterios que emanaban de ellas, habían cambiado antes de dictarse la sentencia. La Corte IDH determinó que, si la práctica estatal y los criterios internos se habían modificado, de tal forma que estos guardaban concordancia con los estándares del SIDH, el Estado había dado cumplimiento a la obligación que resulta del artículo 2 de la $\mathrm{CADH}$; es decir, la adopción de disposiciones a nivel interno.

Lo decidido por la Corte IDH en el caso Cruz Sánchez, es de gran importancia debido a que permite observar un correcto entendimiento por parte del Tribunal, de su rol subsidiario respecto de las autoridades nacionales. En el referido caso, las autoridades judiciales peruanas habían adecuado sus interpretaciones y los criterios emanados de ellas a estándares 
internacionales, por lo que la Corte IDH reconoció que no existía violación alguna al artículo 2 de la CADH. De esta manera, el Estado cumplió con dicho mandato, y con ello, generó la innecesaria revisión por parte de un organismo internacional.

Este reconocimiento puede ser considerado superficial, ya que representa una buena práctica que permite lograr un equilibrio en el SIDH, honrando la naturaleza subsidiaria del mismo que, como ya se pudo mencionar, está establecida en la propia CADH. El pronunciamiento de la Corte IDH sobre la adecuada actuación de las autoridades nacionales y que la tome en cuenta para el análisis acerca del cumplimiento el artículo 2, tiene un gran valor. Esto, ya que no sólo legitima el actuar de la Corte IDH como un organismo que respeta la soberanía de los Estados, sino que también resguarda los derechos de las víctimas de violaciones de derechos humanos.

Finalmente, en el caso Duque Vs. Colombia, la Corte IDH analizó la exclusión del señor Duque de la posibilidad de obtener una "pensión de sobrevivencia" tras la muerte de su pareja, con base en que se trataba de una pareja del mismo sexo. En dicho caso, el Estado colombiano alegó que el hecho ilícito internacional había cesado y que había sido subsanado o reparado. Para ello, indicó que la sentencia C-336 de 2008 y la sentencia T-051, así como las subsiguientes, habían modificado la normativa interna colombiana. Esta ahora permitía que se paguen pensiones de sobrevivencia a parejas del mismo sexo, por la muerte de uno de ellos. Actualmente, el señor Duque contaría con un recurso adecuado y efectivo para solicitar el pago de dicha pensión (Corte IDH. Caso Duque Vs. Colombia, 2016, párr. 129).

$\mathrm{Al}$ respecto, tanto las partes, como la $\mathrm{CIDH}$, informaron a la Corte IDH sobre la modificación que la Corte Constitucional de Colombia había realizado a la legislación interna colombiana, con el fin de dar acceso a las pensiones de sobrevivencia para parejas del mismo sexo (Corte IDH. Caso Duque Vs. Colombia, 2016, párr. 130).

La Corte IDH destacó el significativo avance jurisprudencial realizado por el Estado de Colombia por medio de su Corte Constitucional desde el año 2008. En cuanto a los efectos retroactivos del cambio normativo, dicho desarrollo jurisprudencial constituyó un progreso importante con el objetivo de hacer cesar el trato discriminatorio que resultaba contrario a los derechos convencionales (Corte IDH. Caso Duque Vs. Colombia, 2016, párr. 133). Asimismo, constató que el dinero que podría corresponderle como prestación dejada de percibir por el señor Duque, en caso de que la pensión de sobrevivencia le fuera concedida, abarcaría únicamente los últimos tres ańos anteriores a la presentación del reclamo. Los demás, prescribirían conforme al Código Sustantivo del Trabajo (Corte IDH. Caso Duque Vs. Colombia, 2016, párr. 134).

La Corte IDH señaló que, aunque el señor Duque pudiera solicitar una pensión de sobrevivencia sin que fuera objeto de discriminación, y esta le fuera otorgada, no existía una certeza sobre si el reconocimiento tendría efectos retroactivos. Es decir, efectos retroactivos hasta el momento en que el señor Duque había sido objeto del trato diferente en el año 2002. En ese sentido, la Corte IDH indicó que era razonable concluir que el hecho ilícito internacional del cual había sido víctima el señor Duque, aún no habría sido subsanado en su totalidad. Esto, puesto que los pagos retroactivos que podría percibir, no serían equivalentes a los que habría percibido en caso de no haber sido tratado de forma diferente y discriminatoria (Corte IDH. Caso Duque Vs. Colombia, 2016, párrs. 136-137).

Teniendo en cuenta todo lo anterior, la Corte IDH concluyó que el Estado era responsable por la violación al derecho a la igualdad y no discriminación, en perjuicio del señor Duque, toda vez que no se le permitió acceder en condiciones de igualdad a la pensión de sobrevivencia establecida en la normativa interna colombiana (Corte IDH. Caso Duque Vs. Colombia, 2016, párr. 138). 
Sin embargo, en relación a la alegada violación del artículo 2 de la $\mathrm{CADH}$, la Corte IDH consideró que, atendiendo a la evolución normativa y jurisprudencial en Colombia, respecto del reconocimiento y protección a parejas conformadas por personas del mismo sexo, esta no contaba con elementos suficientes para concluir que existiera una violación al deber de adoptar disposiciones de derecho interno. En vista de lo anterior, la Corte IDH concluyó que el Estado no era responsable por la violación del artículo 2 de la CADH (Corte IDH. Caso Duque Vs. Colombia, 2016, párr. 139).

De esta forma, el caso Duque representa un nuevo avance en la aplicación del principio de subsidiariedad por la Corte IDH, plasmado en las sentencias que esta emite, específicamente en lo relacionado con el artículo 2 de la CADH. Al igual que en el caso Cruz Sánchez, puede observarse que la Corte IDH asume un rol subsidiario frente a normas o prácticas corregidas a nivel nacional, sobre las que ya no cabe un pronunciamiento de carácter internacional.

La Corte IDH, además de legitimar su actuación, incentiva a los Estados a cumplir con las obligaciones derivadas del artículo 2 de la $\mathrm{CADH}$, pues si cumplen con dichas obligaciones, no serán objeto de condenas por parte del Tribunal Interamericano. La Corte IDH ha demostrado que tomará en consideración que los Estados hayan realizado las gestiones necesarias para proteger y garantizar los derechos a nivel interno.

Por otro lado, así como representa un nuevo avance respecto del análisis de la responsabilidad por el incumplimiento del artículo 2 de la $\mathrm{CADH}$, el caso Duque, también ejemplifica los retos a los que se enfrenta la Corte IDH. Retos relacionados al análisis de otras obligaciones derivadas de la $\mathrm{CADH}$ y que también pueden analizarse aplicando el principio de subsidiariedad. En este sentido, el caso Duque presentaba acciones por parte del Estado colombiano, más allá de los cambios legislativos, que podrían entenderse como suficientes para reparar las violaciones a nivel interno. Sin embargo, a ojos de la Corte IDH aquellas serían insuficientes, pues los montos otorgados por la pensión alimenticia, si bien tendrían un carácter retroactivo, su cantidad no ascendería a lo deseado por la víctima.

Dicho análisis resulta más delicado puesto que requiere que la Corte IDH realice un análisis, por un lado, sobre las acciones que deben adoptar los Estados para reparar las violaciones de derechos humanos (mismas que según la Corte IDH deben ser acciones suficientes) y, por otro lado, sobre la aplicación del principio de subsidiariedad (a través del cual, el Tribunal Americano considere que ya no existe la necesidad de un pronunciamiento de carácter internacional). Así, la Corte IDH ha determinado en algunos casos que las obligaciones estatales se encuentran cumplidas en lo relativo a las modificaciones normativas. Sin embargo, por lo que respecta a otras acciones o prácticas emprendidas por el Estado, la Corte IDH aún considera que hay una falta de claridad. Es decir, hasta qué punto el análisis de la Corte IDH podría resultar subsidiario y en qué medida su intervención podría convertirse en una intromisión en el actuar del Estado; así sea que esta tenga por objetivo, el exigir el cumplimiento de las obligaciones establecidas en la CADH.

\section{Conclusiones}

El DIDH presenta, inevitablemente, la tensión entre el ejercicio de los derechos humanos y la soberanía que los Estados han cedido, en cierto grado, ante los organismos y los mecanismos internacionales. Como se ha mencionado, las teorías clásicas en las que el derecho nacional está por encima del derecho internacional, o a la inversa, resultan insuficientes para responder a esta tensión. Sobre todo, en la actualidad, donde los casos presentados ante organismos internacionales, ya no versan únicamente sobre derechos respecto de los cuales no sea posible establecer ninguna restricción.

La Corte IDH, máximo organismo regional existente en el continente americano para 
la protección de los derechos humanos, dentro del marco de la OEA, ha debido enfrentarse al análisis de casos desenvolviendo un papel que complementa a aquel de las jurisdicciones internas de los diferentes países.

El principio de subsidiariedad guía a los organismos internacionales, como la Corte IDH, para que, en cumplimiento de sus funciones, actúen de forma complementaria y subsidiaria a las atribuciones soberanas de los Estados. La precisión de los límites y de las facultades de cada uno, les permite tomar decisiones más legítimas, ya que otorgan a los Estados un margen de actuación. Esto, respetando sus circunstancias internas y particulares, sin descuidar que los Estados cumplan con sus obligaciones internacionales en materia de derechos humanos.

Todavía hace falta que la Corte IDH ahonde en la comprensión del principio de subsidiariedad y de su naturaleza complementaria, buscando aplicarla no sólo en lo relacionado con cambios normativos, sino también a las acciones y prácticas tomadas a nivel interno por parte de los Estados que buscan cumplir con la CADH.

La aplicación del principio de subsidiariedad no debe provocar recelo ni temor. Debe ser observado como un mecanismo útil que permite la sanción de violaciones a derechos humanos. También, debe ser entendido como una herramienta que permite solucionar la tensión inherente de los mecanismos internacionales de derechos humanos. Si es aplicado y entendido correctamente, el principio de subsidiariedad, este legitima y fortalece a los organismos internacionales, que, como la Corte IDH, deben intentar aplicarlo cada vez más a fin de consolidar y fortalecer la plena defensa y vigencia de los derechos humanos.

\section{Referencias bibliográficas}

Carozza, P. (2003). Subsidiarity as a Structural Principle of International Human Rights Law. Scholarly Works, Paper 564. https://doi.org/10.2307/3087103

Ferrer, E., Pelayo, C. (2014). Artículo 2, deber de adoptar disposiciones de derecho interno. En C. Steiner, P. Uribe (eds.). Convención Americana sobre Derechos Humanos, comentada, 1, 69-98. <http://www.corteidh.or.cr/tablas/30237.pdf >.

González, P. (2017). Reconfiguración de la relación entre el derecho internacional de los derechos humanos y el derecho nacional sobre la base del principio de subsidiariedad. Revista del Instituto de Investigaciones Jurídicas de la UNAM, 17, 717-748. http:// dx.doi.org/10.22201/iij.24487872e.2017.17.11050.

\section{Convenciones, tratados y conferencias}

OEA (1969). Convención Americana sobre Derechos Humanos (también llamada Pacto de San José de Costa Rica). Suscrita, tras la Conferencia Especializada Interamericana de Derechos Humanos, el 22 de noviembre de 1969 en la ciudad de San José en Costa Rica y entró en vigencia el 18 de julio de 1978.

\section{Sentencias}

Corte IDH (2000). Caso Cantoral Benavides Vs. Perú. Fondo. Sentencia de 18 de agosto de 2000. Serie C No. 69.

- (2001). Caso "La Última Tentación de Cristo" (Olmedo Bustos y otros) Vs. Chile. Sentencia de 5 de febrero de 2001. Serie C No. 73. 
- (2002). Caso Hilaire, Constantine y Benjamin y otros Vs. Trinidady Tobago. Sentencia de 21 de junio de 2002. Serie C No. 94.

- (2003). Caso "Cinco Pensionistas". Sentencia de 28 de febrero de 2003. Serie C No. 98.

- (2004). Caso "Instituto de Reeducación del Menor" Vs. Paraguay. Excepciones Preliminares, Fondo, Reparaciones y Costas. Sentencia de 2 de septiembre de 2004.

- (2005). Caso Caesar Vs. Trinidad y Tobago. Sentencia de 11 de marzo de 2005. Serie C No. 123.

- (2005). Caso Raxcacó Reyes Vs. Guatemala. Fondo, Reparaciones y Costas. Sentencia de 15 de septiembre de 2005.

- (2006). Caso Acevedo Jaramillo y otros Vs. Perú. Interpretación de la Sentencia de Excepciones Preliminares, Fondo, Reparaciones y Costas. Sentencia de 24 de noviembre de 2006. Serie C No. 15.

- (2006). Caso La Cantuta Vs. Perú. Fondo, Reparaciones y Costas. Sentencia de 29 de noviembre de 2006. Serie C No. 162.

- (2006). Caso Almonacid Arrellano y otros Vs. Chile. Excepciones Preliminares, Fondo, Reparaciones y Costas. Sentencia de 26 de septiembre de 2006.

- (2014). Caso Tarazona Arrieta y otros Vs. Perú. Excepción Preliminar, Fondo, Reparaciones y Costas. Sentencia de 15 de octubre de 2014. Serie C No. 286.

- (2015). Caso Comunidad Campesina de Santa Bárbara Vs. Perú. Excepciones Preliminares, Fondo, Reparaciones y Costas. Sentencia de 1 de septiembre de 2015. Serie C No. 299.

- (2015). Caso Cruz Sánchez y otros Vs. Perú. Excepciones Preliminares, Fondo, Reparaciones y Costas. Sentencia de 17 de abril de 2015. Serie C No. 292.

- (2015). Caso Maldonado Vargas y otros Vs. Chile. Fondo, Reparaciones y Costas. Sentencia de 2 de septiembre de 2015. Serie C No. 300.

- (2015). Caso Velásquez Paiz y otros Vs. Guatemala. Excepciones Preliminares, Fondo, Reparaciones y Costas. Sentencia de 19 de noviembre de 2015. Serie C No. 307.

- (2016). Caso Duque Vs. Colombia. Excepciones Preliminares, Fondo, Reparaciones y Costas. Sentencia de 26 de febrero de 2016. Serie C No. 310. 